\title{
Pemberdayaan Ekonomi Aktivis Aisyiyah Melalui Pelatihan Ecoprint Ramah Lingkungan
}

\author{
Akif Khilmiyah ${ }^{*}$, Arni Surwanti2** \\ 1, Program Doktor Psikologi Pendidikan Islam, Program Pasca Sarjana, Universitas Muhammadiyah Yogyakarta \\ 2. Program Studi Magister Manajemen, Program Pasca Sarjana, Universitas Muhammadiyah Yogyakarta \\ Jln Brawijaya, Tamantirto Kasihan Bantul, 55183 \\ Email: akif.khilmiyah@umy.ac.id \\ DOI: $10.18196 / p p m \cdot 34 \cdot 301$
}

\begin{abstract}
Abstrak
Permasalahan yang ditemukan di Dusun Brajan Tamantirto Kasihan Bantul, antara lain: adanya potensi bahan alami berupa aneka ragam tumbuhan yang belum dimanfaatkan dengan baik, kurangnya ketrampilan ibu ibu aktivis aisyiyah dalam mengelola potensi alam desa untuk meningkatkan penghasilan, dan belum membudayanya batik yang ramah lingkungan di kalangan ibu ibu aktivis aisyiyah. Tujuan Program Kemitraan Masyarakat ini yaitu: (1) memberikan solusi berupa pemanfaatan potensi bahan alam yang dimiliki dusun Brajan, dan (2) meningkatkan keterampilan aktivis aisyiyah dalam menciptakan batik yang alami. (3) menambah sumber ekonomi keluarga. Kontribusi Program Kemitraan Masyarakat ini yaitu Melalui pelatihan pembuatan ecoprint dengan memanfaatkan bahan alami yang ada di lingkungan Dusun Brajan Tamantirto Kasihan, maka dapat memberikan manfaat langsung terhadap kehidupan aktivis aisyiyah dan masyarakat Brajan di bidang sosial dan ekonomi melalui ketrampilan batik ecoprint serta dapat meningkatkan kualitas sumberdaya melalui pemberdayaan ibu-ibu aktivis Aisyiyah Ranting Tamantirto Tengah yang meliputi Sembilan Kelompok Majlis Taklim di Dusun Brajan Tamantirto Kasihan. Hasil Pelatihan ecoprint ini (1) dapat meningkatkan kesadaran aktivis Aisyiyah untuk memanfaatkan potensi desa untuk meningkatkan kesehjahteraan keluarga. (2) dapat meningkatkan ketrampilan dalam membuat batik yang berasal dari bahan alam. (3) dapat menambah pendapatan keluarga.
\end{abstract}

Kata Kunci: Pemberdayaan ekonomi, Pelatihan ecoprint, Aktivis Aisyiyah.

\section{PENDAHULUAN}

Dalam Tanwir Surabaya pada 19-21 Januari 2018, organisasi perempuan Muhammadiyah, Aisyiyah, mengangkat tema "Gerakan Pemberdayaan Ekonomi Perempuan, Pilar Kemakmuran Bangsa". Tema ini sangat relevan, setidaknya terlihat dari mulai maraknya gerakan-gerakan ekonomi berbasis komunitas. Gerakan ini yang jika tidak diorganisasi dengan kelembagaan dan jejaring yang apik, bukan tidak mungkin sekadar jadi euforia.

Dalam forum tanwir itu, Aisyiyah sebagai gerakan Islam, dakwah amar makruf nahi munkar dan tajdid ingin membangunkan kesadaran kolektif bangsa bahwa modalitas yang dimiliki perempuan bisa menjadi fundamen dan pilar dalam membangun ekonomi. Dalam studinya yang berjudul Social Capital a Multifaceted Perspective, perempuan dengan modal sosial (social capital) yang kuat bisa mendorong pertumbuhan berbagai sektor ekonomi. Modal sosial ini diwujudkan dalam bentuk kekohesifan sosial, semangat gotong-royong, tolongmenolong, rasa dan semangat saling memberi (reciprocity), rasa saling percaya (trust), dan jejaring sosial (social networking) (Dasgupta, Partha, dan Saralgedin, 2000). Modalitas ini menjadi energi dalam membangun keberlanjutan usaha dan bertahannya kekuatan ekonomi suatu masyarakat, terutama ekonomi keluarga. 
Laporan Pembangunan Manusia yang dipublikasikan UNDP (2017) mengungkapkan bahwa terjadinya kesenjangan Indeks Pembangunan Manusia (IPM) Indonesia 2016 antara lakilaki dan perempuan. Indeks Pembangunan Manusia untuk kaum perempuan sebesar 0,66, tertinggal dibandingkan laki-laki sebesar 0,712. Perempuan tertinggal dalam rata-rata lama sekolah, jumlah yang tamat pendidikan menengah, pendapatan nasional per kapita, dan partisipasi kerja. Kesenjangan pendapatan dan partisipasi kerja antara laki-laki dan perempuan adalah yang paling mencolok.

Kesenjangan ini juga dialami oleh ibu-ibu aktivis Aisyiyah yang kurang memiliki ketrampilan dalam mengelola potensi alam di lingkungan desanya. Ibu-Ibu Aisyiyah lebih banyak aktif dalam kegiatan keagamaan, diantaranya: pengajian rutin, majelis Taklim dan sebagainya. Aktivitas ekonomi yang memberdayakan masyarakat dalam bentuk meningkatkan penghasilan keluarga belum banyak dilakukan. Kegiatan-kegiatan lain yang berupaya untuk memberdayakan perempuan di lingkungan masyarakatnya, sehingga perempuan itu dapat mandiri dalam kehidupan keluarganya juga belum banyak dilakukan.

Permasalahan lainnya yang ditemukan di Dusun Brajan, Tamantirto, Kasihan, Bantul yaitu: (1) Adanya potensi bahan alami berupa aneka ragam tumbuhan yang belum dimanfaatkan dengan baik, (2) Kurangnya ketrampilan ibu ibu aktivis Aisyiyah ranting Tamantirto Tengah dalam mengelola potensi alam desa untuk meningkatkan penghasilan, dan (3) Belum membudayanya batik yang ramah lingkungan di kalangan ibu ibu aktivis Aisyiyah.

Oleh karena itu Program Kemitraan Masyarakat ini bekerjasama dengan organisasi Aisyiyah di tingkat ranting mencoba untuk memberikan solusi berupa pemanfaatan potensi bahan alam yang dimiliki dusun Brajan, dan untuk meningkatkan keterampilan aktivis aisyiyah dalam menciptakan tambahan sumber ekonomi keluarga. Hal ini dilakukan dengan pemanfaatan potensi bahan alam yang dimiliki di lingkungan dusunnya dengan membuat batik yang ramah lingkungan. Kegiatannya berupa pemberdayaan ekonomi aktivis Aisyiyah melalui pelatihan ecoprint dengan memanfaatkan bahan alami yang ramah lingkungan.

Kontribusi Program Kemitraan Masyarakat ini adalah dengan mengadakan pelatihan pembuatan ecoprint dengan memanfaatkan bahan alami yang ada di lingkungan Dusun Brajan, Tamantirto, Kasihan sehingga dapat memberikan manfaat langsung terhadap kehidupan aktivis Aisyiyah dan masyarakat Brajan di bidang sosial dan ekonomi melalui ketrampilan batik ecoprint serta dapat meningkatkan kualitas sumberdaya melalui pemberdayaan ibu-ibu aktivis Aisyiyah Ranting Tamantirto Tengah yang meliputi Sembilan Kelompok Majlis Taklim di Dusun Brajan Tamantirto Kasihan. 


\section{METODE PENDEKATAN}

Metode pendekatan atau solusi yang ditawarkan Tim Program Kemitraan Masyarakat (PKM) sebagai berikut: (1) Metode pendekatan yang dilakukan untuk mengatasi masalah belum dimanfaatkannya potensi bahan alami berupa aneka ragam tumbuhan yaitu membangun kesadaran masyarakat dan peduli masyarakat melalui pelatihan pengembangan potensi alam yang ada di lingkungannya; (2) Metode pendekatan yang dilakukan untuk mengatasi masalah kurangnya ketrampilan ibu ibu aktivis Aisyiyah ranting Tamantirto Tengah dalam mengelola potensi alam desa untuk meningkatkan penghasilan dilakukan dengan pelatihan ketrampilan batik yang ramah lingkungan. Pelatihan membuat batik ini diharapkan dapat membekali ketrampilan ibu-ibu aktivis Aisyiyah dalam memberdayakan komunitas masyarakat di lingkungannya masing-masing; dan (3) Metode pendekatan yang dilakukan untuk mengatasi masalah belum membudayanya batik yang ramah lingkungan di kalangan ibu ibu aktivis Aisyiyah dilakukan dengan pelatihan batik ecoprint. Pelatihan batik ecoprint ini dilakukan dengan membuat batik yang memanfaatkan bahan alami yang ramah lingkungan dan menjadi potensi yang ada di lingkungan dusunnya berupa berbagai jenis daun-daunan yang berasal dari berbagai macam tanaman. Pelatihan batik ecoprint ini diharapkan dapat memberdayakan masyarakat untuk menghasilkan produk batik yang berbeda dengan batik pada umumnya, baik dalam hal corak dedaunan maupun pewarnaan yang alami, sehingga dapat menjadi potensi untuk pemberdayaan ekonomi masyarakat, khususnya ibu-ibu dalam mendukung penghasilan keluarganya.

Dengan demikian maka metode pendekatan yang dilakukan kepada Mitra berupa: (1) Pelatihan: Untuk mengubah kesadaran masyarakat sehingga masyarakat peduli terhadap potensi alam yang ada di lingkungannya. (2) Workshop: Untuk membekali ketrampilan ibu-ibu aktivis Aisyiyah dalam membuat batik yang ramah lingkungan. (3) Bimbingan Teknis: Untuk memberikan ketrampilan dalam membuat batik ecoprint yang layak jual dengan memanfaatkan bahan alami yang ramah lingkungan dan menggunakan desain yang menarik dan pewarnaan yang alami. (4) Pendampingan: Untuk mendampingi cara memasarkan produk batik ecoprint ini ke konsumen yang ada di lingkungannya dan mengembangkan ke pasar yang lebih luas, sehingga menghasilkan keuntungan secara finansial.

\section{HASIL DAN PEMBAHASAN}

Program Kemitraan Masyarakat (PKM) ini dilakukan dengan berbagai kegiatan sebagai upaya untuk memberdayakan ibu-ibu aktivis Aisyiyah dan masyarakat Brajan di bidang sosial dan ekonomi melalui ketrampilan batik ecoprint serta dapat meningkatkan kualitas sumberdaya 
melalui pemberdayaan ibu-ibu aktivis Aisyiyah Ranting Tamantirto Tengah yang meliputi Sembilan Kelompok Majlis Taklim di Dusun Brajan Tamantirto Kasihan. Oleh karena itu, berbagai kegiatan yang dilakukan dalam kegiatan PKM ini difokuskan untuk dapat memberdayakan ibu-ibu aktivis Aisyiyah dalam bidang social dan ekonomi. Adapun luaran PKM ini adalah peningkatan kapasitas Kelompok aktivis Aisyiyah Ranting Tamantirto Tengah dalam membuat batik ecoprint; video teknik pembuatan ecoprint yang bisa disimak oleh masyarakat umum. Kegiatan Program Kemitraan Masyarakat ini juga dipublikasikan di jurnal nasional yang diharapkan dapat menjadi acuan bagi kelompok masyarakat lain dalam meningkatkan kapasitas masyarakat dalam memanfaatkan potensi desa dan meningkatkan kesejahteraan masyarakat melalui pelatihan ecoprint.

Hasil pelaksanaan Program Kemitraan Masyarakat (PKM) ini dapat dilihat sebagai berikut:

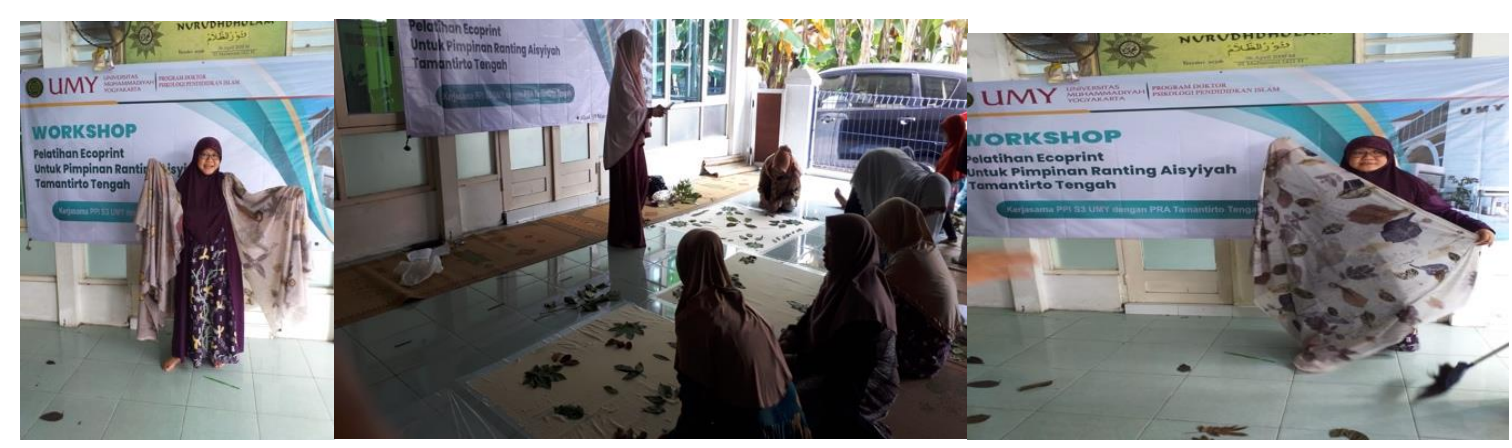

Gambar 1. Penjelasan awal tentang Kerajinan Batik Ecoprint oleh bu Rowiyah.

Materi pelatihan pembuatan batik ecoprint dilakukan melalui langkah-langkah pembuatan batik ecoprint, sebagai berikut:

1. Kain dimordan terlebih dahulu dengan cara kain direbus dengan tawas dan abu soda. Ukurannya 16 gr tawas dan 16 gr abu soda untuk 2 liter air. Kemudian air direbus sampai mendidih. Setelah air mendidih masukkan kain dan rebus 1 jam. Matikan api dan kain tetap direndam dalam air tersebut selama 24 jam.

2. Setelah itu kain diangkat, kemudian dibilas dengan air biasa sampai bersih, selanjutnya kain dijemur sampai kering.

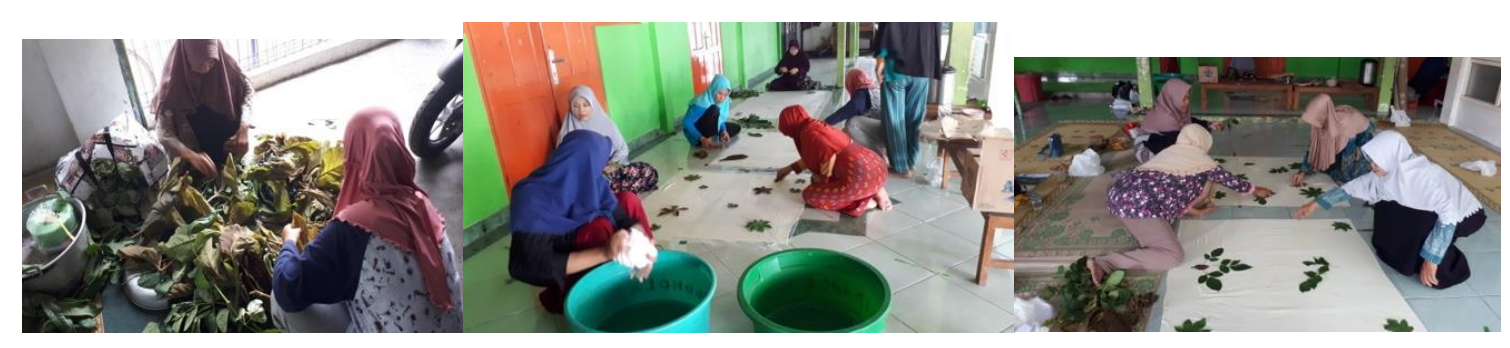


3. Memulai proses produksi dengan memilih daun dan bunga yang akan dipakai untuk membatik. Daun dan bunga yang dipilih usahakan yang mengandung kadar warna kental. Selanjutnya kain dicelupkan pada 2 liter air yang sudah diberi 16 gr tunjung. Ambil 2 lembar kain, yang satu direndam dengan air tunjung, kain yang satu direndam dengan pewarna yang diinginkan. Setelah air merata kain diperas.

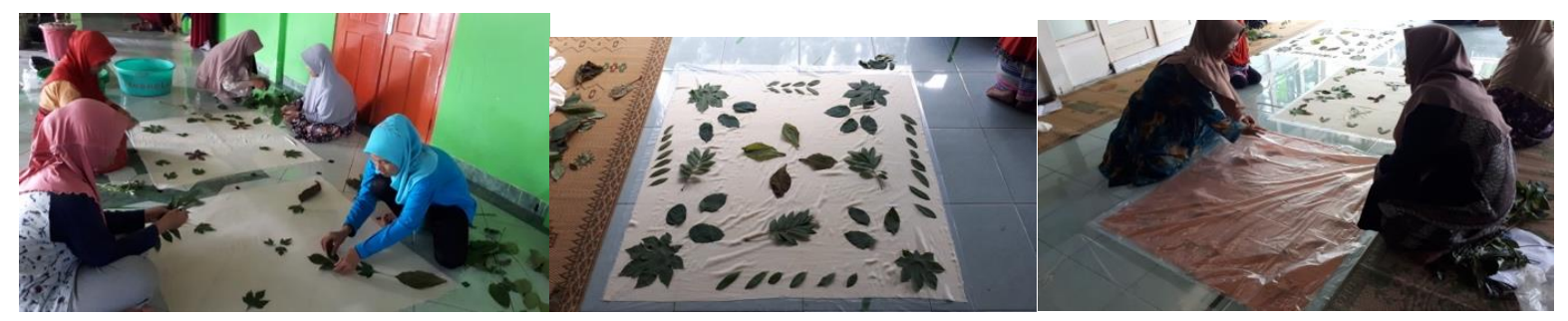

4. Letakkan plastik di atas meja atau lantai yang akan dipakai untuk menempelkan daun. Ukuran plastik sama dengan ukuran kain. Letakkan kain yang telah dicelup air tunjung di atas plastic tersebut. Isolasi kain dengan alas agar kain tidak mudah berubah posisi. Mulailah menempel daun ke atas kain tersebut sesuai selera motif yang diinginkan. Setelah menempel daun, tutuplah kain yang telah dicelup pewarna alam tadi tepat di atasnya.

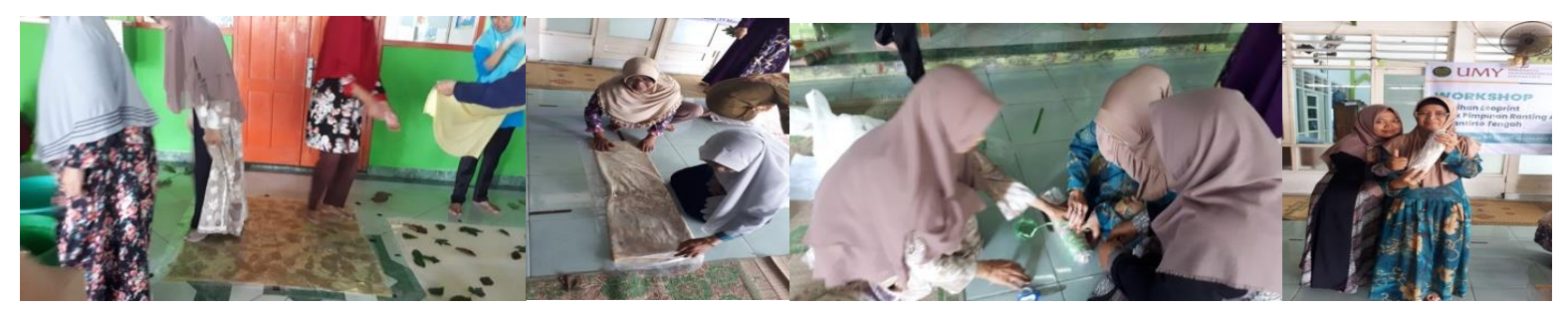

5. Agar warna daun dan bunga bisa lebih menempel bisa dilakukan dengan diinjak injak atau dipukul pukul, setelah merata kain digulung lalu di tali kuat dengan raffia. Setelah menjadi gulungan selanjutnya dikukus selama 3 jam. Selanjutnya diangkat setelah 3 jam, buka gulungan, dedaunan diambil dan direntangkan untuk diangin anginkan.

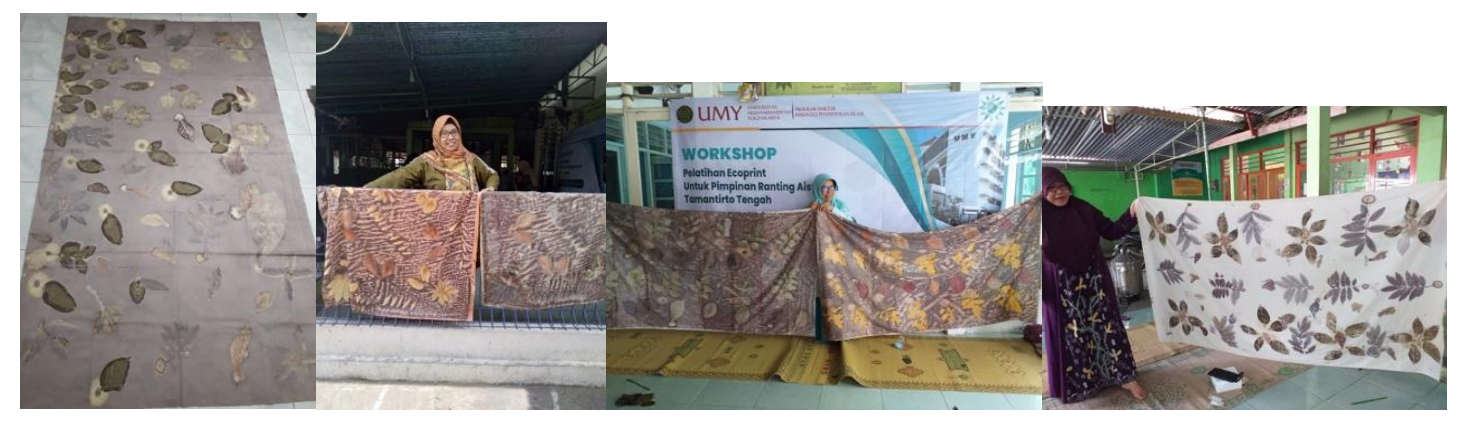




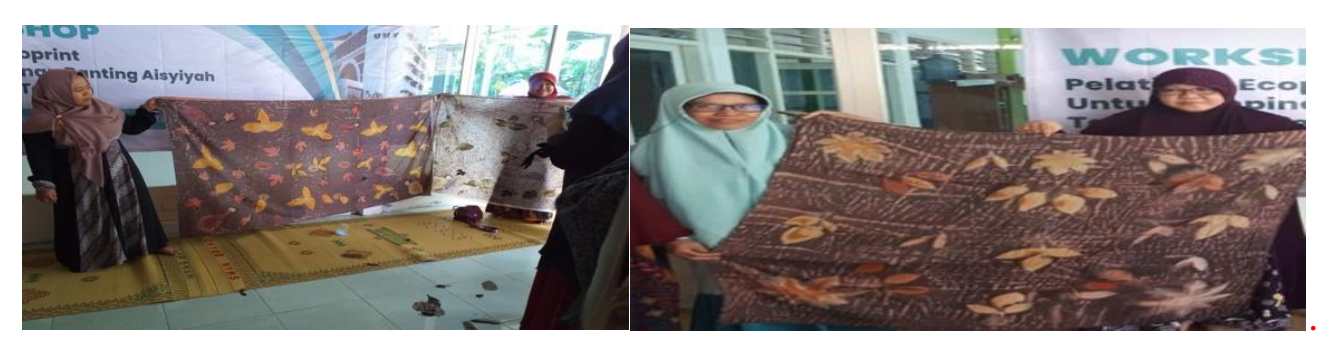

6. Jika sudah kering kain dilipat dan diamkan selama 7 hari. Setelah 7 hari dilakukan fiksasi dengan merendam kain dengan air tawas dengan tujuan untuk mengikat motif dan warna gar tidak luntur. Selanjutnya bilas dengan air biasa sampai jernih, kemudian dijemur sampai kering dan siap untuk dibuat baju sesuai dengan selera.

Semua hasil produksi batik ecoprint yang dibuat oleh ibu ibu aktivis aisyiyah tersebut langsung terjual habis dan hasil penjualannya disumbangkan untuk pembangunan TK.ABA Surya Melati Brajan. Sebagai amal usaha milik Pimpinan Ranting Aisyiyah Tamantirto Tengah.

\section{KESIMPULAN}

Berdasarkan hasil pelaksanaan Program Kemitraan Masyarakat, maka dapat disimpulkan sebagai berikut:

1. Terjadi perubahan kesadaran dan kepedulian msyarakat dalam mengembangkan potensi alam yang ada di lingkungannya sebesar $90 \%$

2. Kemampuan Ibu-ibu aktivis Aisyiyah dalam membuat batik yang ramah lingkungn meningkat sebesar $85 \%$.

3. Bimbingan Teknis yang diberikan kepada ibu ibu aktivis aisyiyah dapat meningkatkan $75 \%$ ketrampilan dalam membuat batik ecoprint yang layak jual dengan memanfaatkan bahan alami yang ramah lingkungan dan menggunakan desain yang menarik dan pewarnaan yang alami.

4. Pendampingan cara memasarkan produk batik ecoprint ini ke konsumen yang ada di lingkungannya $90 \%$ berhasil menjual semua produk yang diciptakan oleh ibu-ibu aisyiyah lewat pengajian dan kegiatan PKK di desa, sehingga menghasilkan keuntungan secara finansial.

\section{Ucapan Terima Kasih}

Tim dosen pengabdi mengucapkan terima kasih kepada Lembaga Publikasi, Penelitian, dan Pengabdian (LP3M) Universitas Muhammadiyah Yogyakarta yang telah mendukung dan memfasilitasi pelaksanaan program ini melalui Surat Penetapan 
Kepala LP3M Nomor 031/PEN-LP3M/I/2020. Selain itu, tim dosen pengabdi juga berterima kasih kepada seluruh Ibu Ibu Aktivis Ranting Aisyiyah Tamantirto Tengah yang telah bersedia menjadi mantra dalam program pengabdian ini.

\section{DAFTAR PUSTAKA}

Endah Saptutyningsih dan Berli PK. 2019. Pemanfaatan Bahan Alami untuk Pengembangan Ecoprint dalam Mendukung Ekonomi Kreatif . Proseding. Semarang: UNIMUS, Vol 2.pp 276.

Norma Puspitasari. 2019. Membentuk Kampung Edukasi Ecoprint melaui Pelatihan Ecoprint Masyarakat Solo Raya. Jurnal Saintech. Politeknik Indonusa Surakarta. Vol 6 No.1.

Profil Desa Tamantirto. 2017. Data Monograf Desa Tamantirto Kecamatan Kasihan, Kabupaten Bantul. DIY.

Fadhil, S. (2018). Pengelolaan Sumberdaya Alam dan Lingkungan Berbasis Pengetahuan dan Kearifan Lokal (Local Wisdom) di Kalimantan, 72-92. Retrieved from https://media.neliti.com/media/publications/196010-ID-pengelolaan-sumber-dayaalam- dan- lingkun.pdf

International Labour Organization. 2017. Pelatihan Keterampilan Pedesaan: Manual Generik Pelatihan untuk Pemberdayaan Ekonomi Pedesaan ( TREE ).

Nissa, R. R., Kp, P., Widiawati, D., \& Sn, M. 2008. Dan Pewarna Alami Untuk Produk Fashion. Jural Tingkat Sarjana Bidang Senirupa Dan Desain, 1-7. Retrieved from Muhammadiyahhttp://jurnal- s1.fsrd.itb.ac.id/index.php/craft/article/view/479/415

Nurfathiyah, P., Mara, A., Siata, R., \& Farida, A. 2011. Pemanfaatan Video sebagai Media Penyebaran Inovasi Pertanian. Jurnal Pengabdian Kepada Masyarakat, (52), 30-36. 